\title{
EL HALLAZGO DE NUEVE SITIOS ARQUEOLÓGICOS CON OUILLCAS EN CAJACAY, BOLOGNESI - ANCASH
}

\author{
Pieter VAN Dalen LUnA \\ Universidad NaCIONAL MAYOR DE SAN MARCoS \\ pvandalen2@hotmail.com \\ Yesenia Huashuayo Casavilca \\ UNIVERSIDAD NACIONAL SAN LUIS GONZAGA DE ICA \\ esperanza_05_1993@hotmail.com \\ Joe Huamaní Perlacios \\ UNIVERSIDAD NACIONAL MAYOR DE SAN MARCOS \\ johuper@hotmail.com
}

\section{RESUMEN}

La cuenca alta del río Fortaleza es un territorio de abundantes sitios arqueológicos, muchos de los cuales corresponden a sitios con pinturas rupestres, en su mayoría asociados a estructuras funerarias tipo chullpas. Esto evidencia la existencia de una amplia y larga tradición cultural rupestre, donde se representan elementos naturales en articulación con el hombre y sus actividades domésticas.

Palabras clave: arqueología, pinturas rupestres, cuenca del río Fortaleza, Cajacay, Ancash

\section{Abstract}

The upper basin of the Fortaleza river is a territory of abundant archaeological sites, many of which correspond to sites with cave paintings, mostly associated with chullpas funerary structures. This evidences the existence of a wide and long cultural rock tradition, where natural elements are represented in articulation with the man and his domestic activities.

KeYwords: Archeology, cave paintings, Fortaleza river basin, Cajacay, Ancash 


\section{Ubicación y Entorno Ambiental}

Los sitios arqueológicos materia del presente estudio, se encuentran ubicados en la cuenca alta del río Fortaleza, en su margen izquierda. Políticamente se encuentran ubicados en el distrito de Cajacay, provincia de Bolognesi, región Ancash. El territorio donde se emplazan los sitios arqueológicos, es un territorio de cuenca alta.

La cuenca del río Fortaleza, perteneciente al sistema hidrográfico del Pacífico, cuenta con un área total de drenaje de 2348 Kilómetros cuadrados y una longitud de 111 kilómetros. Presenta un curso sinuoso, en especial en la cuenca alta donde se caracteriza por presentar un paisaje encajonado, de fondo profundo y quebrado, de un relieve escarpado y abrupto de gran pendiente y estrechas gargantas. El río Fortaleza o Paramonga nace en las alturas de las lagunas de Huamblac y Macato, discurriendo sus aguas por las quebradas de Upapampa y Moyocancha, las cuales en su confluencia dan origen al río Fortaleza. Este río es de régimen muy irregular y torrentoso, presentando marcadas diferencias entre sus descargas extremas (ONERN; 1972). Entre los principales afluentes del río Fortaleza tenemos por la margen izquierda a los ríos: Purísima, Raquia, Corotanca y Capillanía; mientras que por la margen derecha tenemos los ríos: Huayllapampa, Marca, Llaqllin, entre otros.

El territorio del distrito de Cajacay abarca diferentes pisos o regiones naturales ecológicas, como la quechua en la localidad de Cajacay, la región Suni en las partes medio altas de Santa Rosa y la región Puna en las alturas de Cajacay en la divisoria de Aguas con el río Purísima y cerca de Conococha. Estos tres pisos naturales presentan diferentes ecosistemas que son el hábitat de numerosas especies florísticas y faunísticas.

\section{Sitios Arqueológicos con Pinturas Rupestres}

\section{Cerro KunKa}

Se encuentra ubicado en una ladera del cerro Kunka y al lado noreste del distrito de Cajacay, cerca de la carretera a Huaraz, en las coordenadas UTM: 18L 0246182E, 8875848N, a una altitud de 4188 metros sobre el nivel del mar. Políticamente se encuentra en la jurisdicción de Seques pampa, distrito Cajacay, provincia Bolognesi, región Ancash. El acceso más adecuado es por la carretera que va hacia Conococha -Huaraz, a media hora en movilidad desde el pueblo de Cajacay, luego se ingresa por un desvío con dirección al noreste a media hora de caminata.

El yacimiento arqueológico se encuentra en un farallón y está conformado por un abrigo rocoso con pintura rupestres o quillcas. El abrigo rocoso tiene una orientación de este a oeste, de 6.70 metros de largo, 2.90 metros de altura y una profundidad al interior de 7.60 metros. En la parte plana de la roca se aprecia pinturas de color rojo, que corresponden a varios paneles:

Panel 1: Ubicado en la parte superior. Corresponde a 8 motivos no identificados por el mal estado de conservación, por lo que solo se observa manchas irregulares de color rojo. Los motivos son de tamaño mediano, de $2 \mathrm{~cm}$ a $20 \mathrm{~cm}$ de alto y de $2 \mathrm{~cm}$ a $8 \mathrm{~cm}$ de ancho.

Panel 2: Ubicado debajo del panel 1. Corresponde a 32 motivos no definidos, motivos antropomorfos, geométrico, abstractos y variado; algunos de los cuales presentan superposición, por lo que corresponderían a dos fases. Los motivos más antiguos son de color rojo intenso (fase 1) y son superpuestos por motivos mas tardíos de color rojo anaranjado; siendo estos a su vez superpuestos por otros motivos de color rojo (Fase 3). 


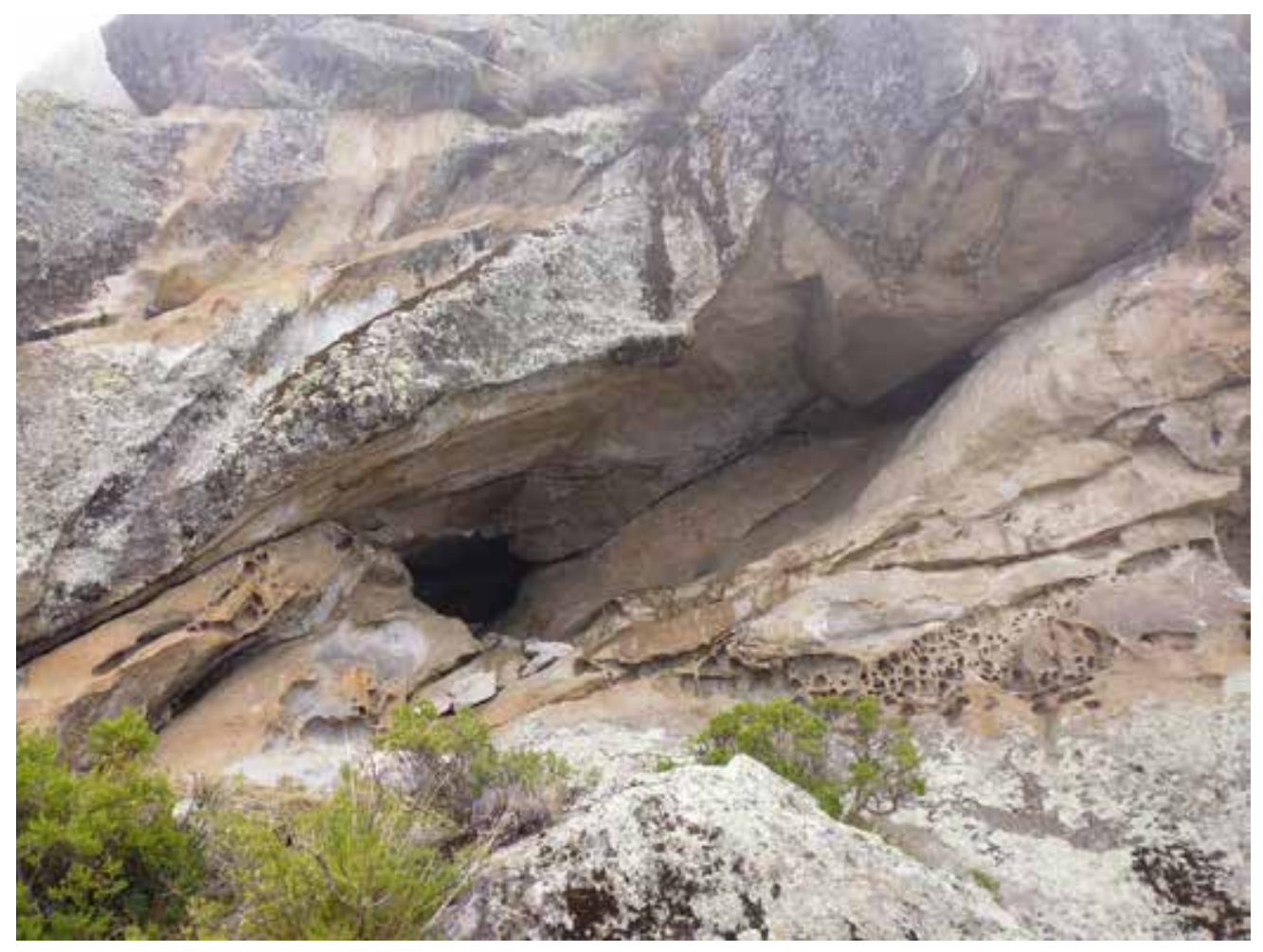

Figura 1: Vista panorámica del abrigo rocoso del Cerro Kunka tomada desde el lado Sur.

- Fase 1: Pintura color rojo intenso: Está conformado por 19 motivos no definidos (a manera de manchas de color rojo) y 3 motivos geométricos a manera de " $\mathrm{X}$ " (aves en vuelo), que tienen un promedio de $12 \mathrm{~cm}$ por $10 \mathrm{~cm}$.

- Fase 2: Pintura de color anaranjado: Está conformado por 2 motivos no definidos (manchas) y 1 motivo antropomorfo que se encuentra con los brazos extendidos hacia arriba y con las piernas abiertas, cuya medida es de $16 \mathrm{~cm}$ de altura.

- Fase 3: Pintura de color rojo: Está conformado por 4 motivos antropomorfos muy deteriorados (a manera de 4 manchas pequeñas y medianas) que miden un promedio de $0.06 \mathrm{~cm}$ a $0.13 \mathrm{~cm}$ de alto y un ancho que varía entre $0.07 \mathrm{~cm}$ a $0.09 \mathrm{~cm}$. Además, hay otros 2 motivos antropomorfos en acción de caminar, uno de ellos presenta un tocado en la cabeza a manera de 3 líneas diagonales y verticales, así mismo el brazo derecho se encuentra flexionado hacia arriba, mientras que el otro brazo se encuentra tendido portando algo en la mano al parecer una vara. También hay un motivo geométrico a manera de sol irradiado, conformado por 18 destellos; las dimensiones son de $8 \mathrm{~cm}$ de diámetro. El sol se ubica por encima de los motivos antropomorfos.

Panel 3: Ubicado en el lado sur del abrigo, conformado por dos motivos geométricos.

La existencia de pintura rupestre entre los peñascos y abrigo rocoso nos permiten asociar al periodo precerámico, además de no haber hallado material cerámico en los alrededores. El estado de 
conservación es regular. Las pinturas rupestres se encuentran alteradas en su mayoría por los factores climáticos y medioambientales. Este abrigo rocoso sirve como refugio de animales ovinos que dejan abundante estiércol.

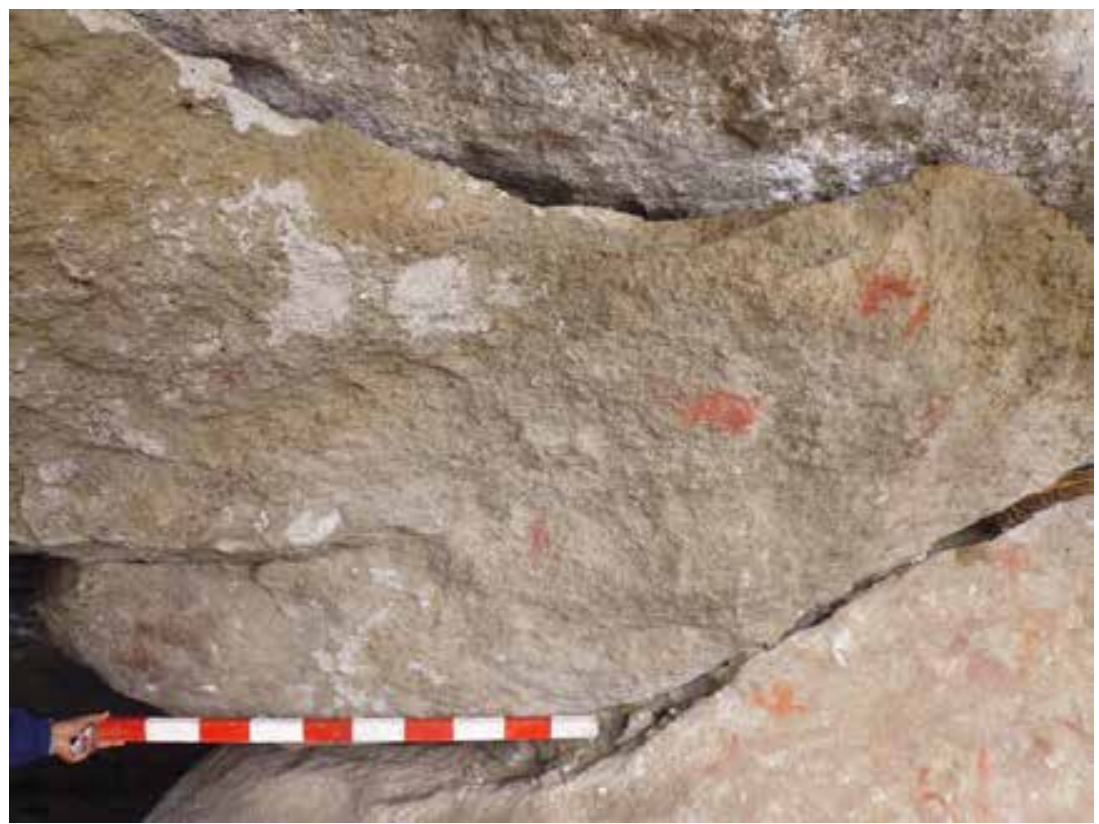

Figura 2: Vista Panorámica del panel 1 del abrigo rocoso del Cerro Kunka.

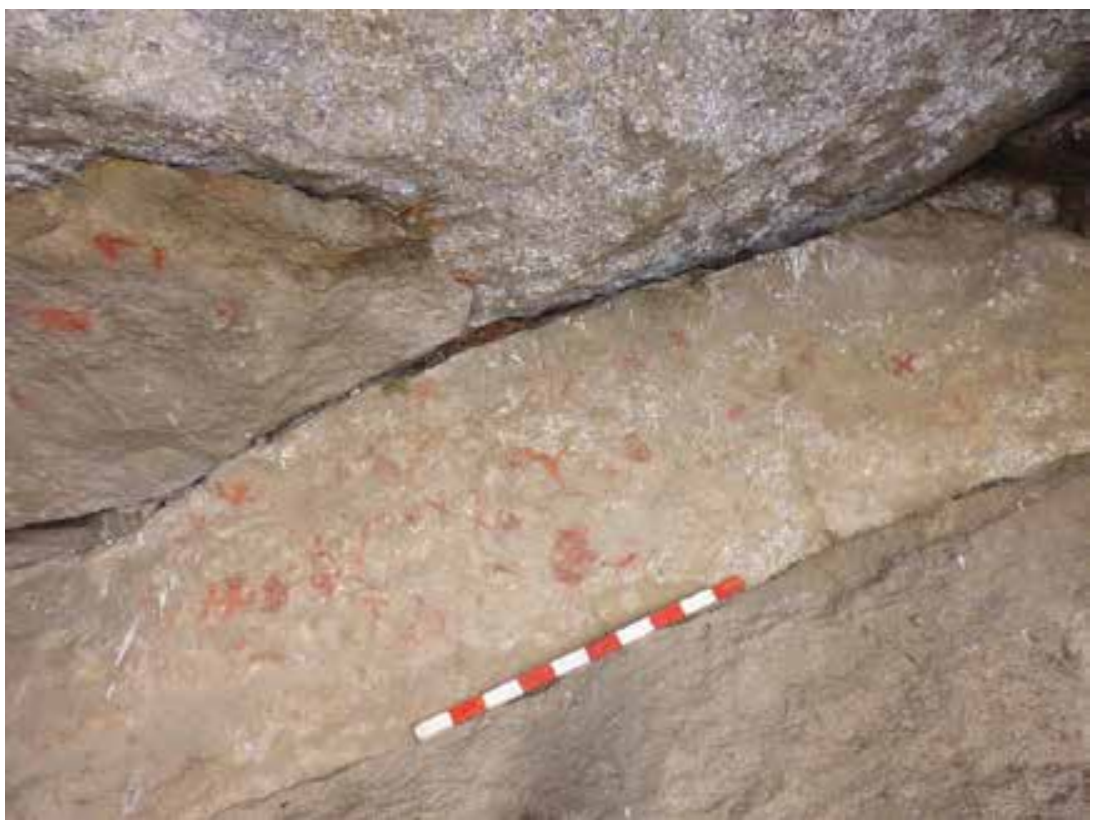

Figura 3: Vista Panorámica del panel 2 del abrigo rocoso del Cerro Kunka. 

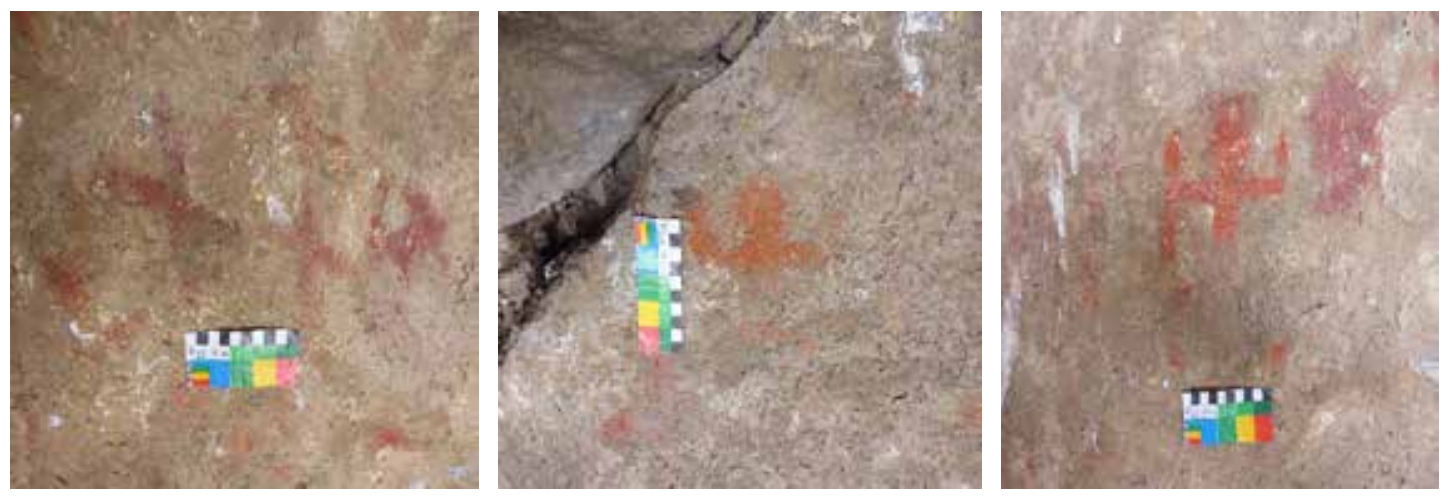

Figuras 4, 5 y 6: Vista de detalle de las superposiciones del panel 2, abrigo rocoso del Cerro Kunka.
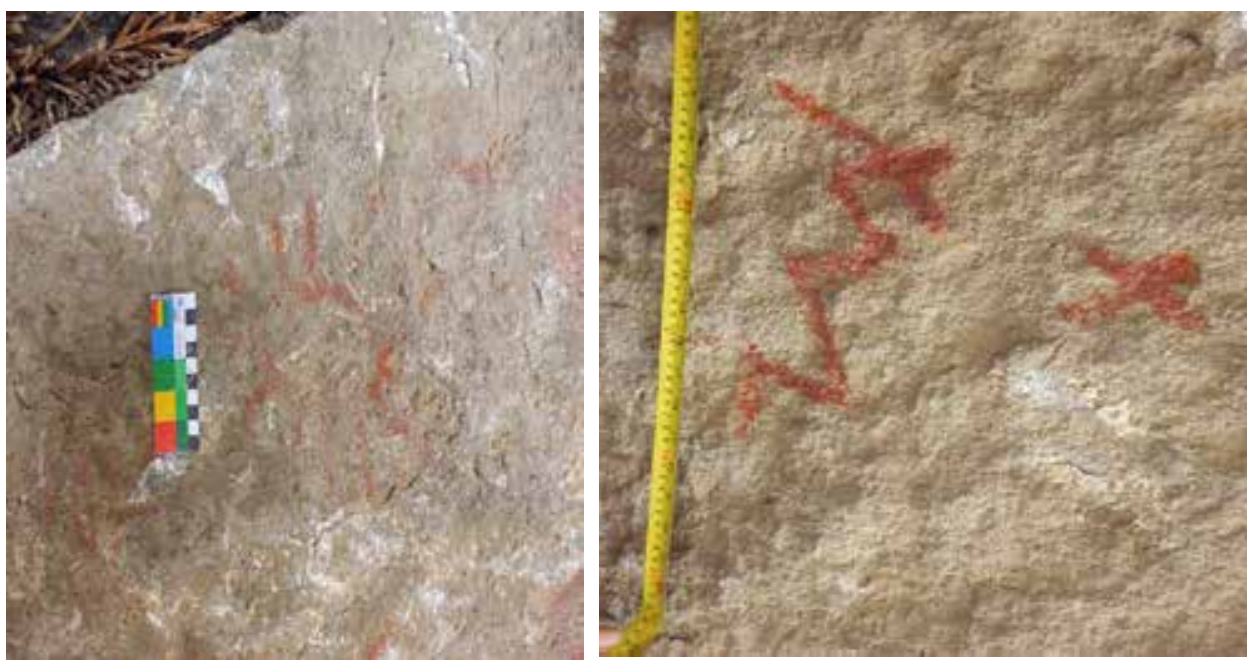

Figura 7: Izquierda: Vista de detalle de motivo geométrico, sol irradiado del panel 2 del Cerro Kunka. Figura 8: Derecha: Vista de detalle de motivos geométricos del panel 3 del Cerro Kunka.

\section{Pinturamachay}

En el quechua ancashino, el término "Pinturamachay" significa "cueva donde se encuentra pintura". Se encuentra ubicado en la ladera media de una quebrada pequeña, al lado noreste del distrito de Cajacay, en las coordenadas UTM: 18L 0244115E, 8875147N, a una altitud de 3872 m.s.n.m. Políticamente se encuentra en la jurisdicción de Seques pampa, distrito de Cajacay, provincia Bolognesi, Región Ancash. El acceso más adecuado es por la carretera que va hacia Conococha -Huaraz, a media hora en movilidad hasta el anexo de Seques pampa, luego se ingresa por un camino que asciende una ladera por medio de las chacras con dirección al noreste (aproximadamente 1 hora de caminata). 


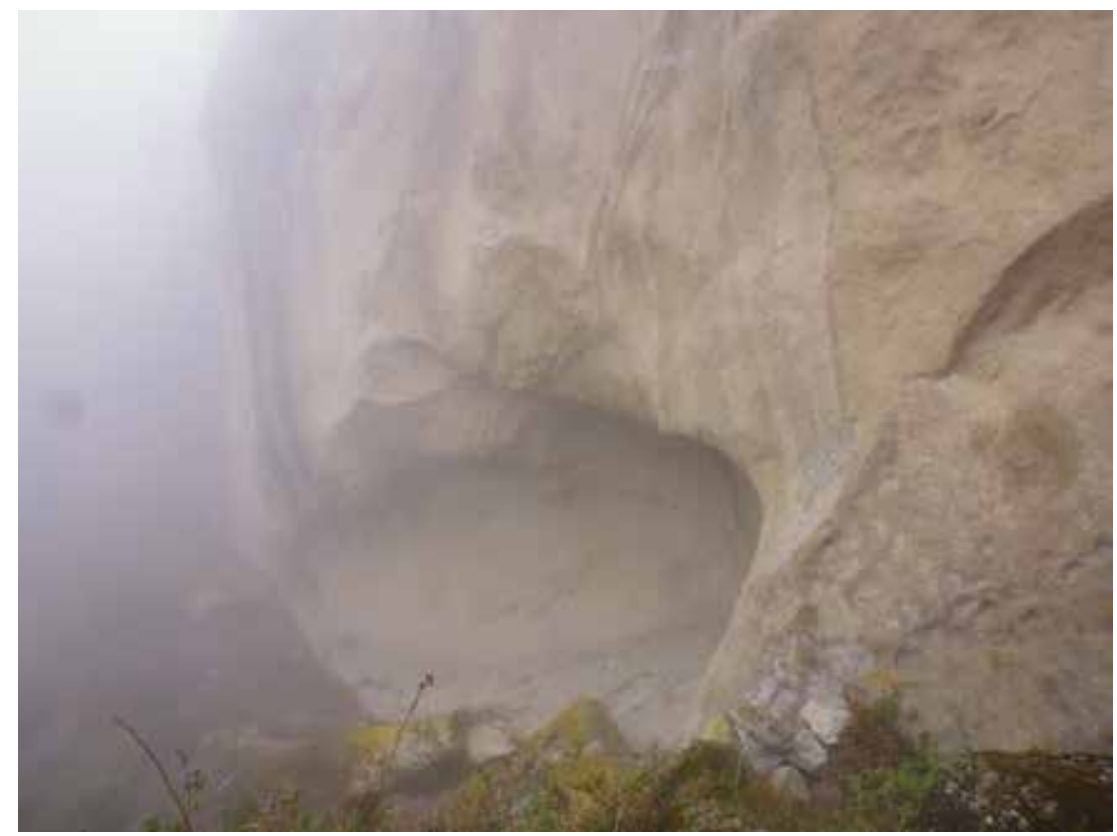

Figura 9: Vista panorámica del abrigo rocoso de Pinturamachay, tomada desde el lado Este.

El yacimiento arqueológico se encuentra en un farallón y está conformado por un abrigo rocoso con evidencias de pintura rupestre. El abrigo rocoso tiene una orientación de este a oeste, de 34.70 metros de largo, 9 metros de altura y una profundidad al interior de 5.60 metros. En la pared plana de la roca se aprecia pinturas de color rojo. Las representaciones eran cerca de 100 motivos, aunque la erosión de la superficie ha borrado el $30 \%$ del total, ocupando desde la parte extrema y media del abrigo rocoso. Los paneles de oeste a este son:

Panel 1: Se emplaza en el lado extremo derecho del abrigo rocoso, conformado por un motivo zoomorfo, con características de un zorro que se encuentra en posición de perfil, cuyo rostro se dirige hacia el lado sur, con las orejas paradas y cola enroscada, de $20 \mathrm{~cm}$ de largo y $8 \mathrm{~cm}$ de alto.
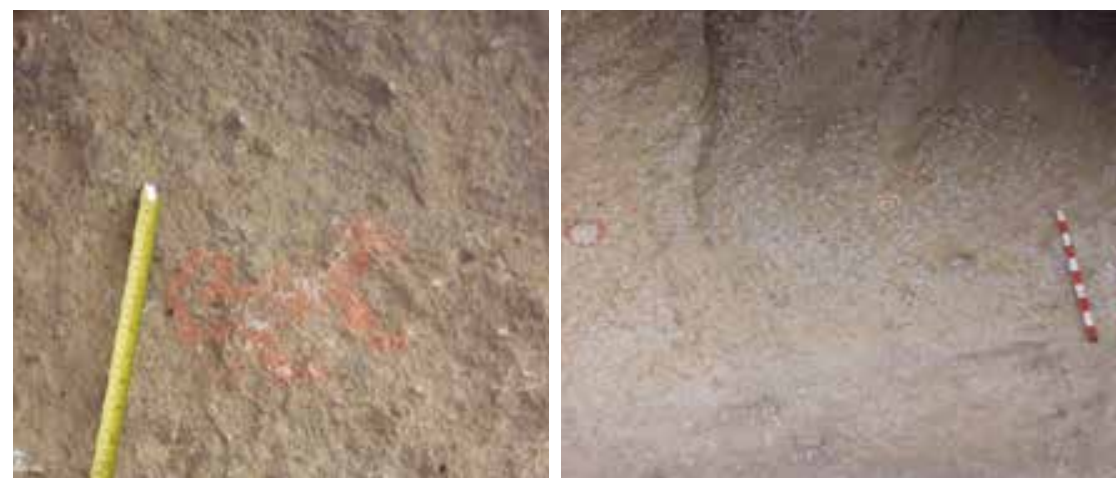

Figura 10: Izquierda: Vista de detalle de motivo Zoomorfo correspondiente al panel 1, de Pinturamachay. Figura 11: Derecha: Vista de detalle de motivos geométricos correspondiente al panel 2. 
Panel 2: compuesto por 3 motivos: 2 círculos de color rojo y dibujados de un solo trazo y 1 círculo concéntrico de cuatro dibujos alternados de color blanco y rojo.

Panel 3: Ubicado en el lado este del panel 2, conformado por una banda horizontal pintada de color rojo, orientada de noreste a sureste, de 3.90 metros de largo.

Panel 4: Se ubica en el lado izquierdo del abrigo rocoso, se trata de una fila de motivos geométricos, zoomorfos y abstractos; conformados por 18 círculos de color rojo, 26 círculos con un punto concéntrico, 2 círculos dobles con punto concéntricos, 14 círculos a maneras de manchas alineadas en una fila, un motivo zoomorfo; y hacia su derecha un motivo antropomorfo en posición de perfil, cuyo rostro se encuentra deteriorado por factores ambientales sin apreciar sus rasgos, mientras que de su cabeza sobresale una cabellera en forma serpenteante. En la parte superior del motivo antropomorfo hay una hilera de círculos adosados entre sí, presentando hacia el lado izquierdo pequeños motivos fitomorfos. Al extremo norte (parte superior) hay grandes motivos de color rojo y blanco muy deteriorados.

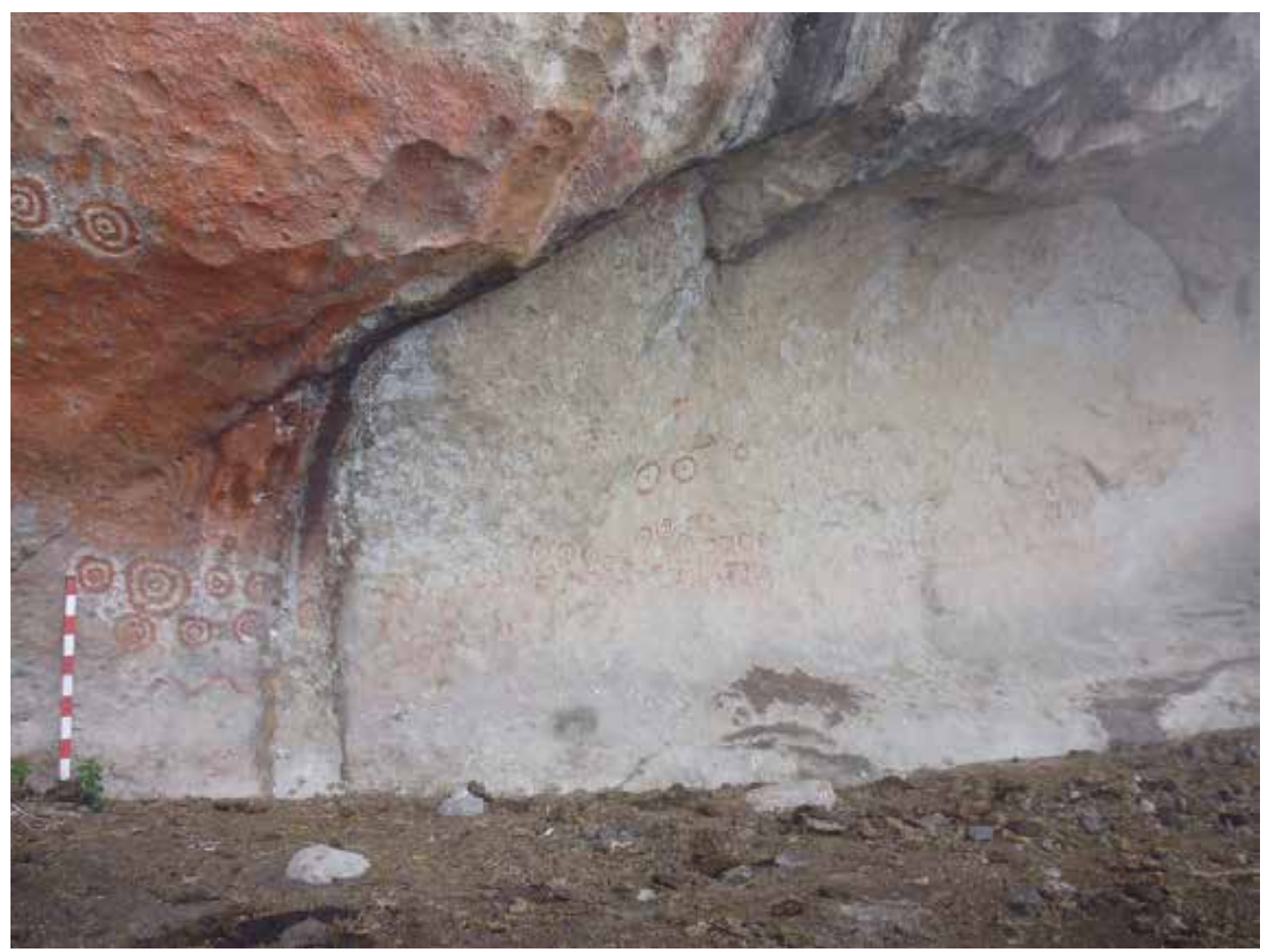

Figura 12: Vista panorámica de motivos del panel 4, Pinturamachay. 


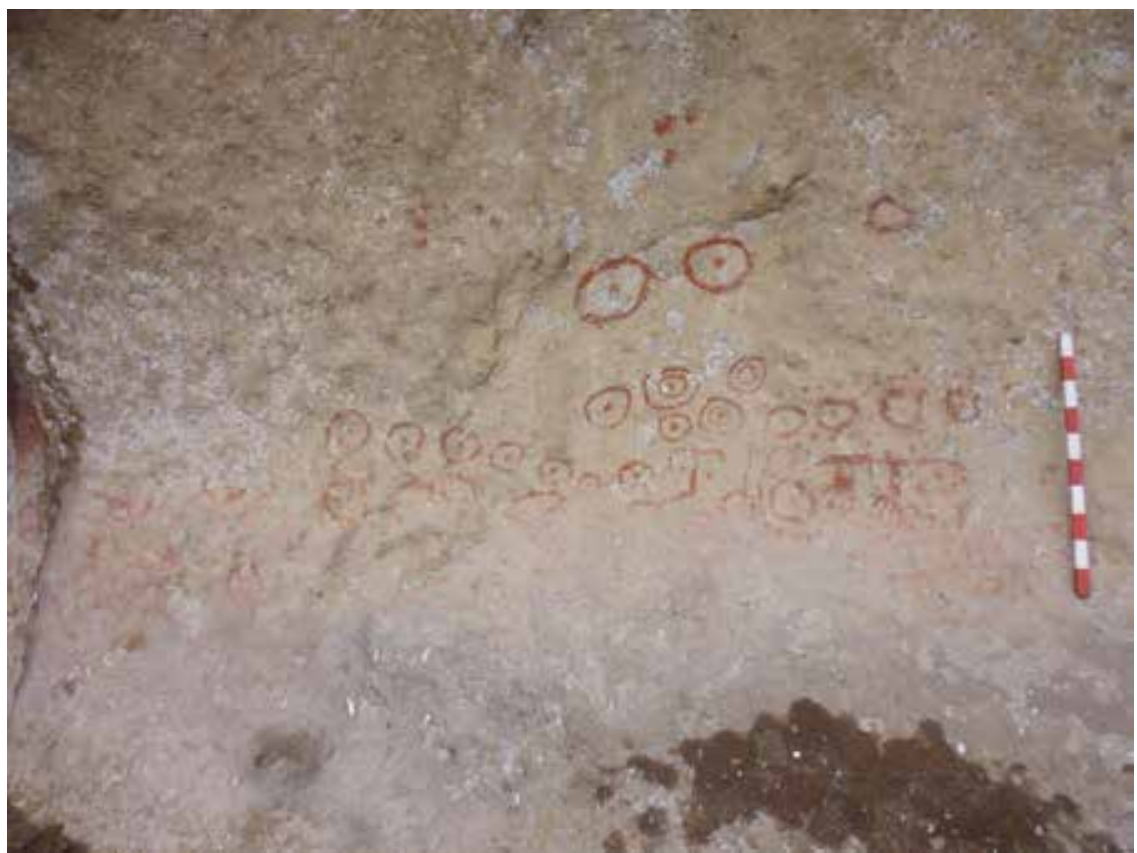

Figura 13: Vista de detalle de motivos geométricos y motivos zoomorfos correspondiente al panel 4.

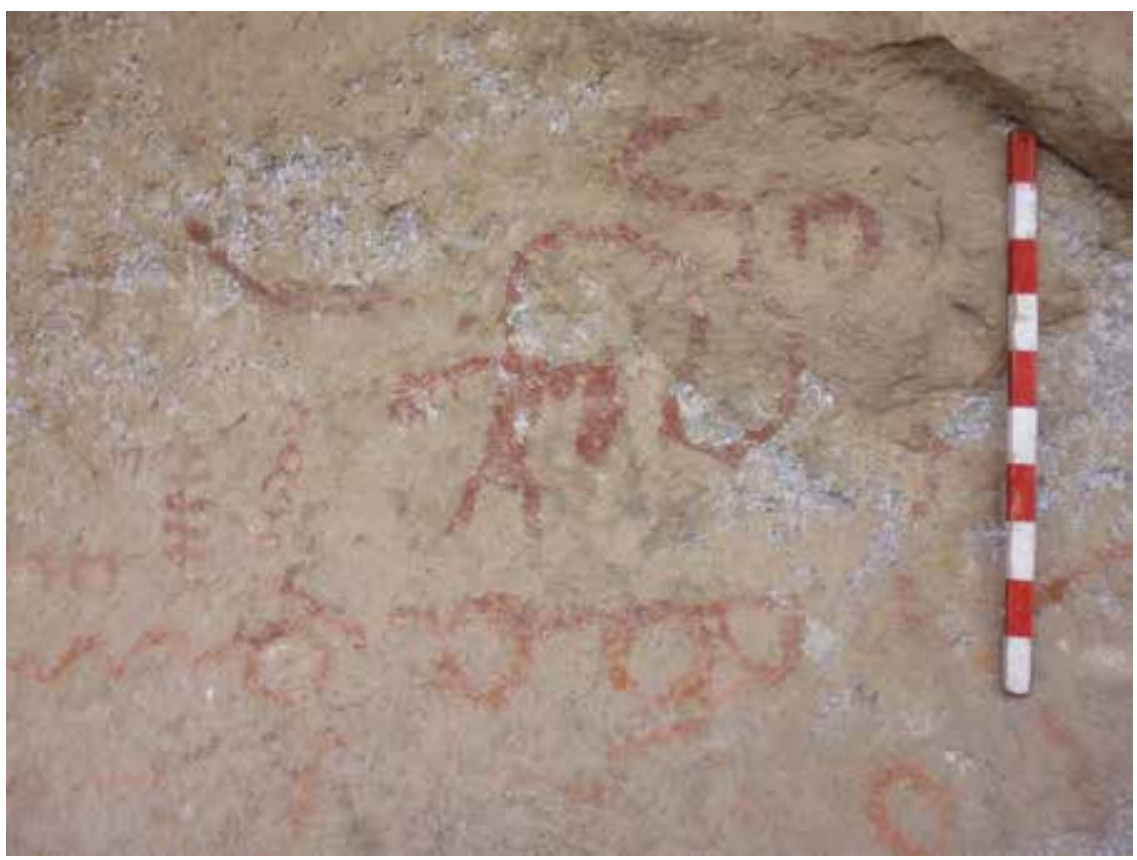

Figura 14: Vista de detalle del motivo antropomorfo, motivo Fitomorfo, motivos geométricos correspondientes al panel 4. 


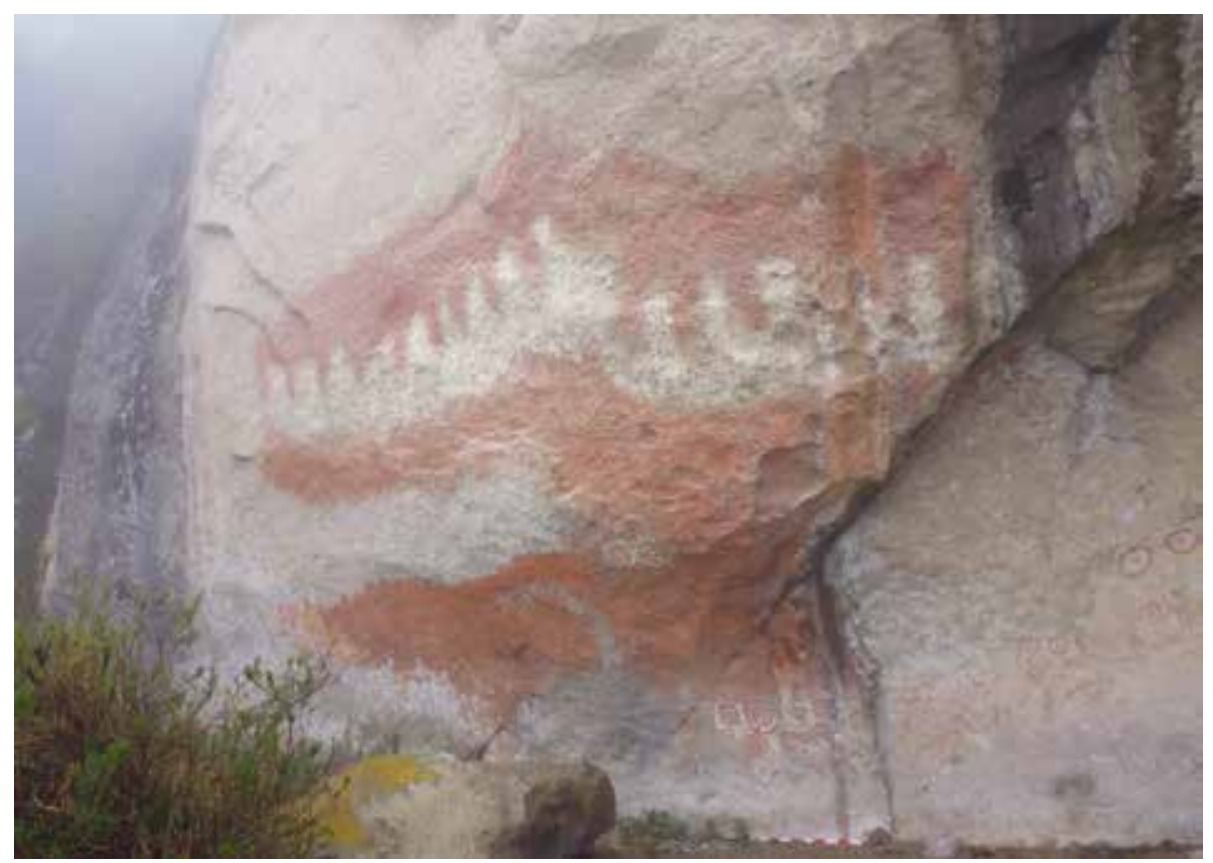

Figura 15: Vista de detalle de la gran dimensión de pictografía roja y blanco ubicada en el lado extremo noreste del abrigo de Pinturamachay.

No es posible determinar con precisión la asociación cronológica de este sitio, aunque no se ha evidenciado material cultural mueble en los alrededores. El estado de conservación es regular. Las pinturas rupestres se encuentran alteradas en su mayoría por los factores climáticos. El abrigo rocoso sirve como refugio de animales que dejan abundante estiércol.

\section{URUNGUAY}

El sitio se ubica en la ladera oeste del cerro Urunguay, en las coordenadas UTM: 18L 0235146 E, $8875906 \mathrm{~N}$, a una altitud de 3055 m.s.n.m. Políticamente se encuentra en la jurisdicción del poblado actual de Cajacay, provincia de Bolognesi, región Ancash. El acceso es mediante un camino de herradura que se dirige desde el actual poblado de Cajacay con dirección al este.

Está conformado por un pequeño abrigo, en la parte alta de un farallón y debajo de un peñasco. Pequeño abrigo conformado por 4 hoyos erosionados de variados tamaños. En la parte interna presenta pictografías de color rojo a manera de manchas dispersas en su totalidad. Presenta regular estado de conservación, la pintura está sufriendo alteración ambiental ya que se encuentra expuesta al aire libre. 


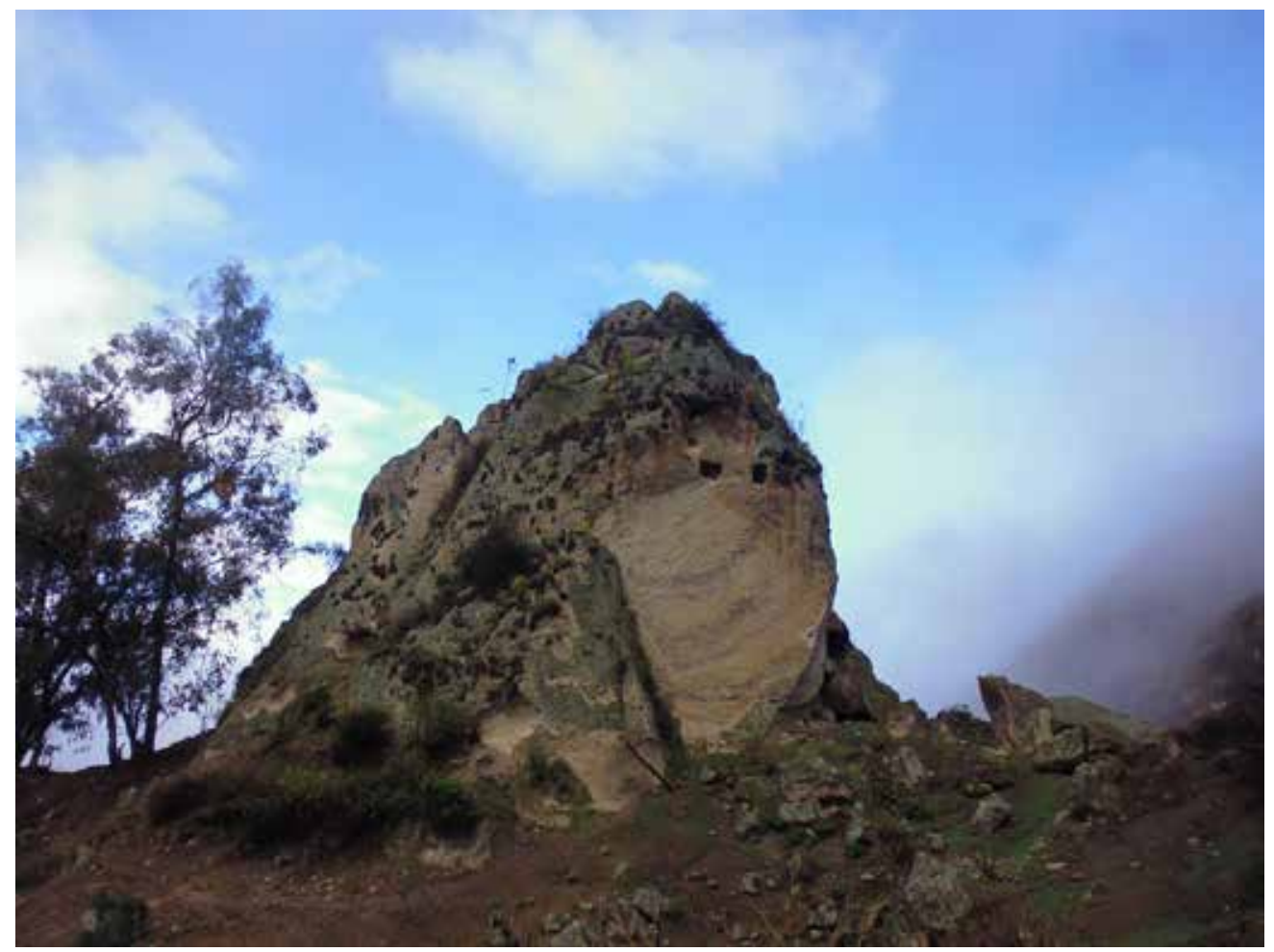

Figura 16: Vista de detalle del sitio Urunguay, tomada desde el lado Este.

\section{Corona}

Se ubica en la cima y ladera del cerro Corona, al lado este de la comunidad de Cajacay. Su localización UTM: 18L 0235164E, 8876714N, a una altitud de 3291 m.s.n.m., en la jurisdicción del pueblo de Cajacay, distrito de Cajacay, provincia de Bolognesi, región Ancash. El acceso es mediante un camino de herradura que se dirige desde el actual poblado de Cajacay con dirección al este, ascendiendo la ladera hasta llegar a la cima del cerro Corona. Presenta tres sectores:

Sector A: Ubicado en la parte media del cerro Corona, conformado por un recinto de planta rectangular que tiene un acceso mediante gradas, orientado de norte a sur, estructura con muros de doble hilera construida a base de piedras canteadas unidas con mortero de barro. El recinto tiene 12 metros de largo por 10 metros de ancho. En el interior se encuentra un pequeño recinto de planta rectangular de 6.30 metros de largo por 4 metros de ancho, que presenta reocupación moderna. Adosado a estas estructuras se encuentra una huanca de forma lanceolada y a unos 10 metros de la huanca (lado oeste del sitio) se hallan terrazas con muros de contención.

Sector B: Ubicado casi en la cima del cerro Corona, conformado por una muralla perimétrica de planta rectangular con muros de doble hilera, construidos con piedras canteadas unidas con argamasa, de 15 metros de largo por una altura de $0.80 \mathrm{~cm}$. En el interior de la muralla presenta 3 recintos de planta rectangular. 
Sector C: Ubicado en la cima del cerro Corona a 40 metros del sector B, conformado por seis estructuras funerarias de planta rectangular que se encuentra construida con piedras canteadas bien trabajadas con mortero de barro. Una de estas chullpas tiene 2.90 metros de largo por 0.90 metros de ancho y 0.70 metros de alto. Presentan vanos orientados de noroeste. También se hallan estructuras de planta circular (16 estructuras), que se distribuyen en todo el esplendor de la cima, estructuras de muros de doble hilera construidas con pequeñas piedras canteadas unidas con mortero de barro, de 1.30 metros de diámetro y con un ancho de muro de 0.56 metros. Se observa piedras alargadas (lajas) perteneciente a los techos. Al interior de algunas estructuras funerarias se hallaron restos óseos humanos.

Según el tipo de material cerámico recuperado se asocia a Intermedio Tardío. Los muros de las terrazas y las estructuras funerarias se encuentran caídos y cubiertos con vegetación arbustiva.

\section{SANTAKUTA}

Se encuentra localizada al pie del cerro Santa Kuta en la margen derecha del caserío de Calquimarca, en una ladera poca pronunciada, en las coordenadas UTM: 18 L 0243983E, 8875516N, a una altitud de 3715 m.s.n.m., en la jurisdicción del poblado de Calquimarca, distrito Cajacay, provincia de Bolognesi, región Ancash. El acceso es mediante un pequeño camino, tomando la ruta desde el anexo de Calquimarca con dirección hacia el este, aproximadamente a unos 15 minutos de caminata.

La zona se encuentra conformada por peñascos y abundante pedregal en los cuales se encuentran abrigos rocosos que contienen contextos funerarios, entre chullpas y cistas.

Abrigo rocoso $\mathrm{N}^{\circ}$ 1: Es un abrigo rocoso cuya orientación es hacia el lado oeste, con un largo de 4.20 metros, altura de 3.10 metros y una profundidad de 3.10 metros. En la entrada al abrigo, se encuentra restos de una chullpa de planta ovalada adosado a la roca natural, con la técnica constructiva a base de piedras planas unidas con argamasa. El diámetro es de 4.60 metros, con un espesor del muro 0.60 metros y una altura conservada de $0.90 \mathrm{~m}$. El estado de conservación es regular, no presenta techo, los alrededores del abrigo está cubierto con vegetación herbácea. Por otro lado en las paredes (parte superior de la arquitectura) se aprecian manchas borrosas de color rojo, un patrón de la zona funeraria.
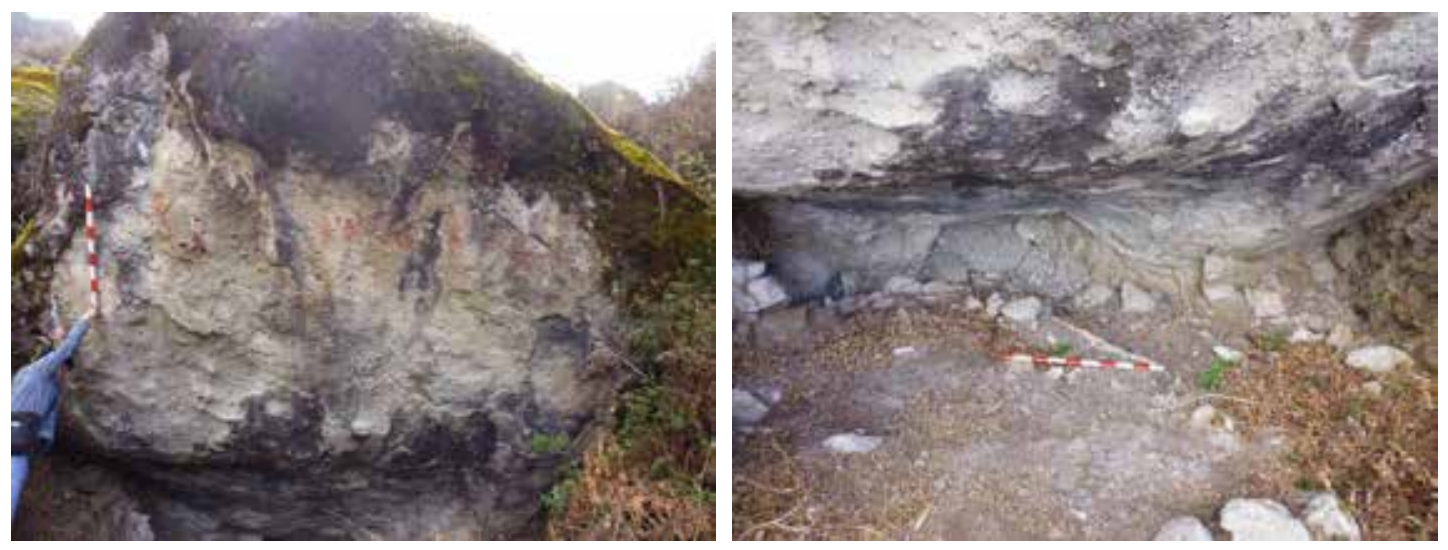

Figura 17: Izquierda: Vista de detalle del Abrigo Rocoso № 1, en la que se aprecia las pinturas rojas. Figura 18: Derecha: Vista de detalle del interior del abrigo Rocoso № 1 . 
Abrigo rocoso $\mathrm{N}^{\circ}$ 02: Se ubica a unos 15 metros hacia el norte del abrigo $\mathrm{N}^{\circ}$ 01, con una orientación hacia el oeste, presenta 6.50 metros de largo por 2 metros de profundidad y una altura de 2.50 metros. En el interior se aprecia osamenta humana tanto de adultos como de niños todas desarticuladas distinguiéndose cráneos deformados, tibia, costillas, vértebras, pelvis y otros huesos fragmentados. El acceso del abrigo se encuentra cercado con un muro de piedras medianas sin argamasa, con abundante vegetación, adosada a la roca natural.
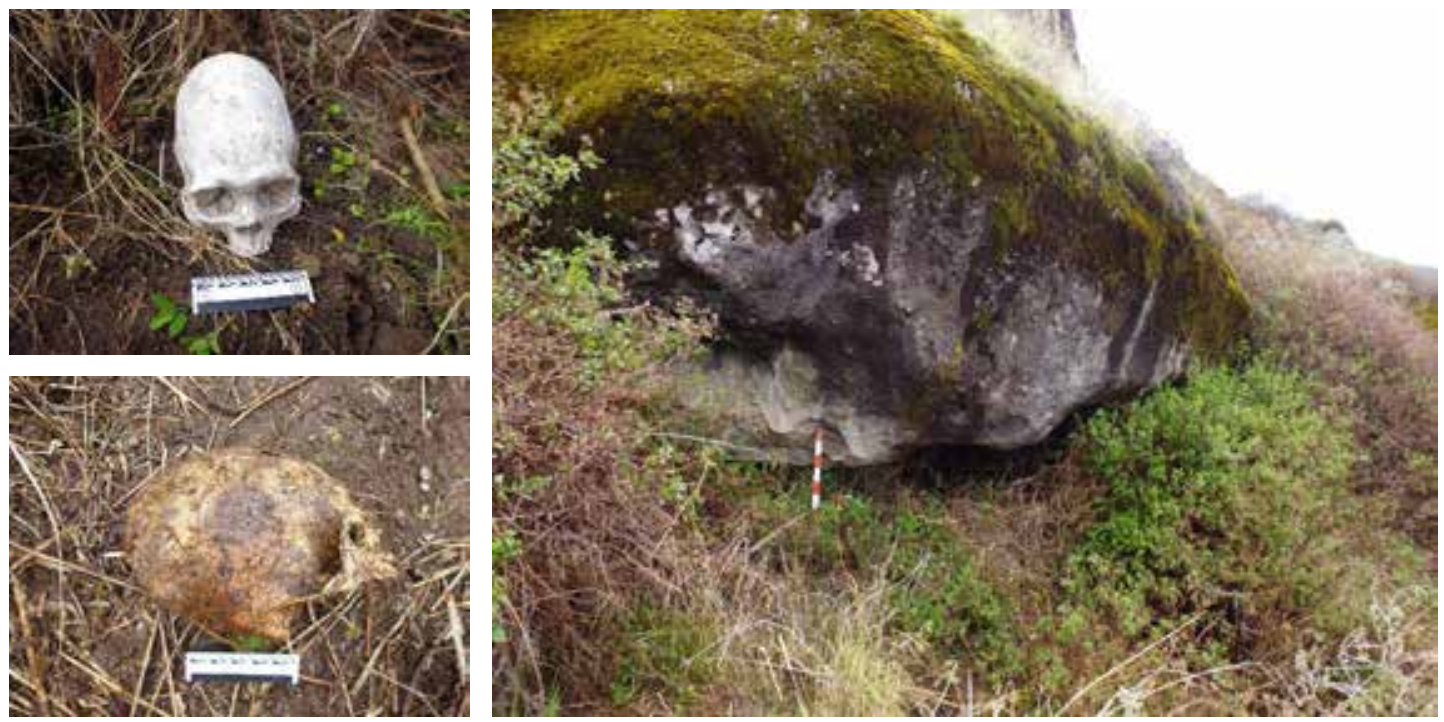

Figura 19: Izquierda: Vista Panorámica del Abrigo Rocoso № 2. Figura 20: Derecha: Vista de detalle del material óseo hallada en el interior del Abrigo Rocoso № 2.

Abrigo rocoso $\mathrm{N}^{\circ}$ 03: Se localiza a unos 40 metros en la parte superior del abrigo rocoso $\mathrm{N}^{\circ} 02$. Está conformado por restos humanos en una oquedad debajo de una peña, en el interior se aprecian osamenta humana articuladas (columnas y pelvis) y desarticuladas como: fragmento de cráneo, vértebras, costillas. Hay una chullpa de morfología rectangular múltiple, adosada a la roca natural, de 2 metros de diámetro por 1 metro de altura conservada. La técnica constructiva es a base de piedras planas unidas con argamasa. Asociados hay fragmentos de cerámica doméstica y material lítico (mano de moler). En las paredes (parte superior de la arquitectura) se aprecian manchas borrosas. 

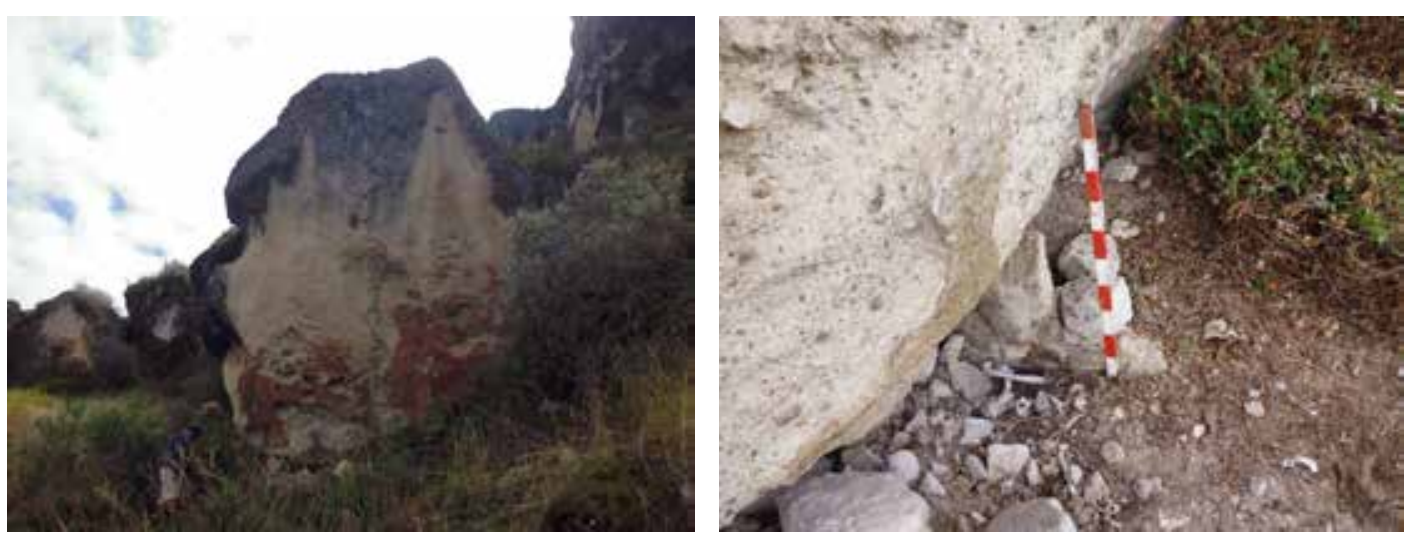

Figura 21: izquierda: Vista panorámica del Abrigo Rocoso № 3 en la que se aprecia las pinturas rojas adherida a la a la roca. Figura 22: Derecha: Vista de detalle de la estructura adosada a la pared del abrigo rocoso.

Abrigo rocoso $\mathrm{N}^{\circ}$ 04: Se localiza al lado norte del abrigo $\mathrm{N}^{\circ}$ 03. En el interior del abrigo se hallan restos humanos desarticuladas como cráneo, vértebras y costillas.

Abrigo rocoso $\mathrm{N}^{\circ}$ 05: Se ubica a unos 40 metros del pie del cerro Santa Kuta y se encuentra con una orientación hacia el oeste, que presenta una pequeña oquedad de 5 metros de ancho por 2 metros de profundidad y una altura de 3 metros. No se aprecia osamenta humana. En las paredes presenta 2 manchas de color rojo de regular dimensión, una de las manchas a manera de pintura rupestre le da forma a un pez donde los ojos son círculos concéntricos de color blanco y sobre esta ella, en un lado extremo presenta superposición decorada de color crema.
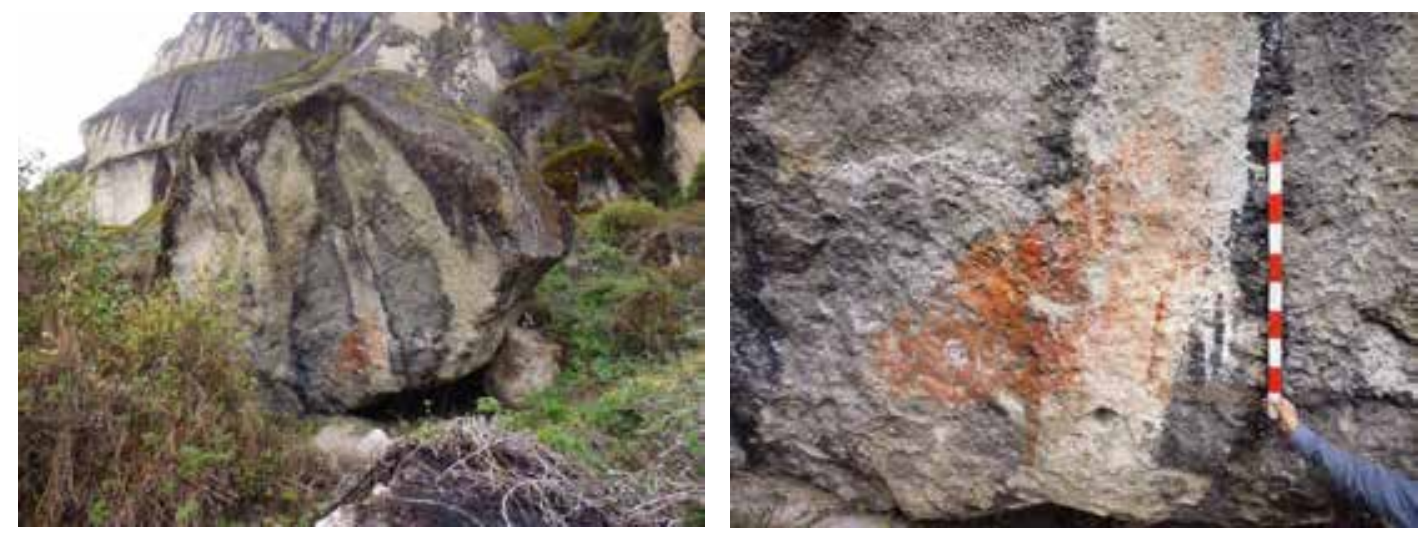

Figura 23: izquierdo: Vista panorámica del Abrigo Rocoso № 5 en la que se aprecia las pinturas rojas adherida a la a la roca. Figura 24: derecha: Vista de detalle del Abrigo Rocoso № 5 en la que se aprecia las pinturas rupestres adherida a la a la roca.

Por las características de las estructuras funerarias, se puede inferior que el sitio corresponde al Intermedio tardío, aunque las pinturas pueden ser más antiguas. Todo en conjunto se encuentra en regular estado de conservación, en su mayoría cubierta con vegetación herbácea y arbustiva. Por otro 
lado, hay evidencia de alteración antrópica con la remoción de los contextos arqueológicos y de la misma forma alteración por factores climáticos.

\section{JOLLQEMARCA}

Se localiza al lado norte del anexo de Calquimarca, ubicado en un pequeño farallón, el cual delimita con la frontera de la provincia Recuay en las coordenadas de UTM: 18L 0244016E, 8875690N, a una altitud de $3730 \mathrm{msnm}$. Políticamente se ubica en los territorios del anexo de Calquimarca, distrito de Cajacay, provincia de Bolognesi, Región Ancash. El acceso es mediante un camino que se dirige desde el poblado de Calquimarca hacia el lado norte, por 10 minutos de caminata, próximo a viviendas contemporáneas.

Se trata de un farallón conformado por roca natural que presenta pintura de color rojo a manera de manchas, y en la parte inferior del peñasco se encuentra muros de contención de terrazas agrícolas (parte de la estructura es contemporánea). Asociada al sitio se encuentra material cerámico y lítico (manos de moler) dispersa sobre la superficie del terreno de cultivo. Así mismo, en la puerta de la casa del Sr: Arango Palomino se aprecian fragmentos antropomorfos de cerámica y material lítico bien trabajado. Según el material cultural identificado, el sitio puede pertenecer a Formativo. Actualmente la zona es aprovechada por la actividad agrícola y casas modernas se ha alterado la mayor parte, quedando algunas evidencias.
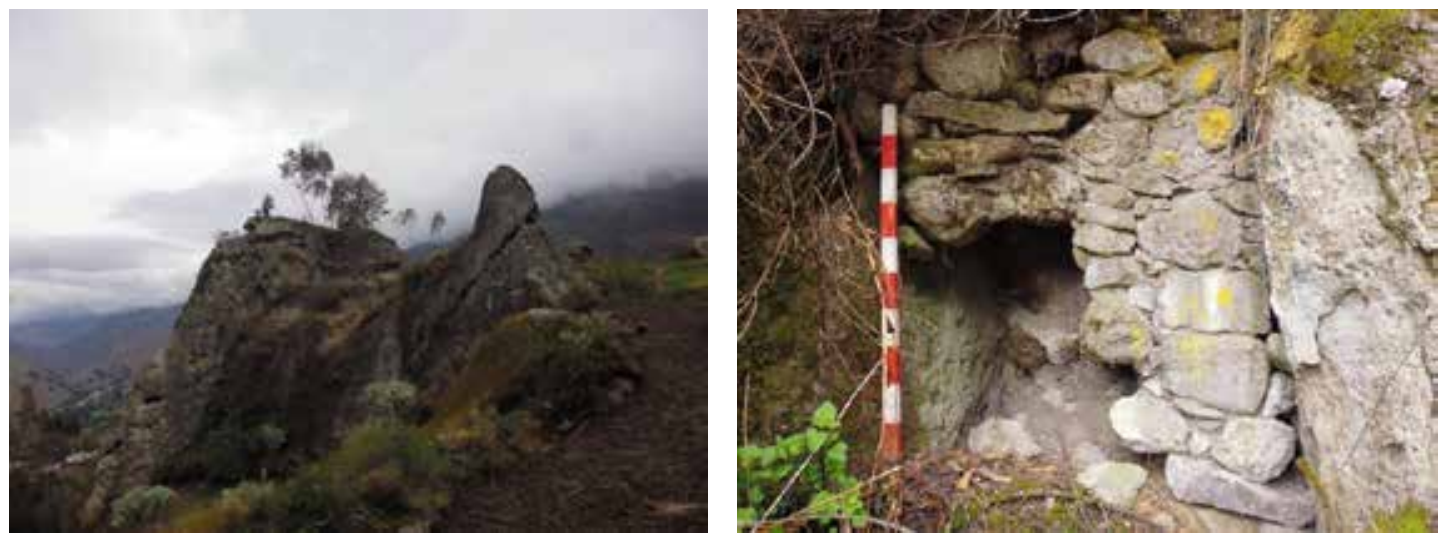

Figura 25: izquierda: Vista Panorámica del sitio Jollqemarca, tomada desde el lado Sur. Figura 26: Derecha: Vista de detalle de los paramentos de terrazas ubicadas en la parte inferior del farallón del sitio Jollqemarca. 

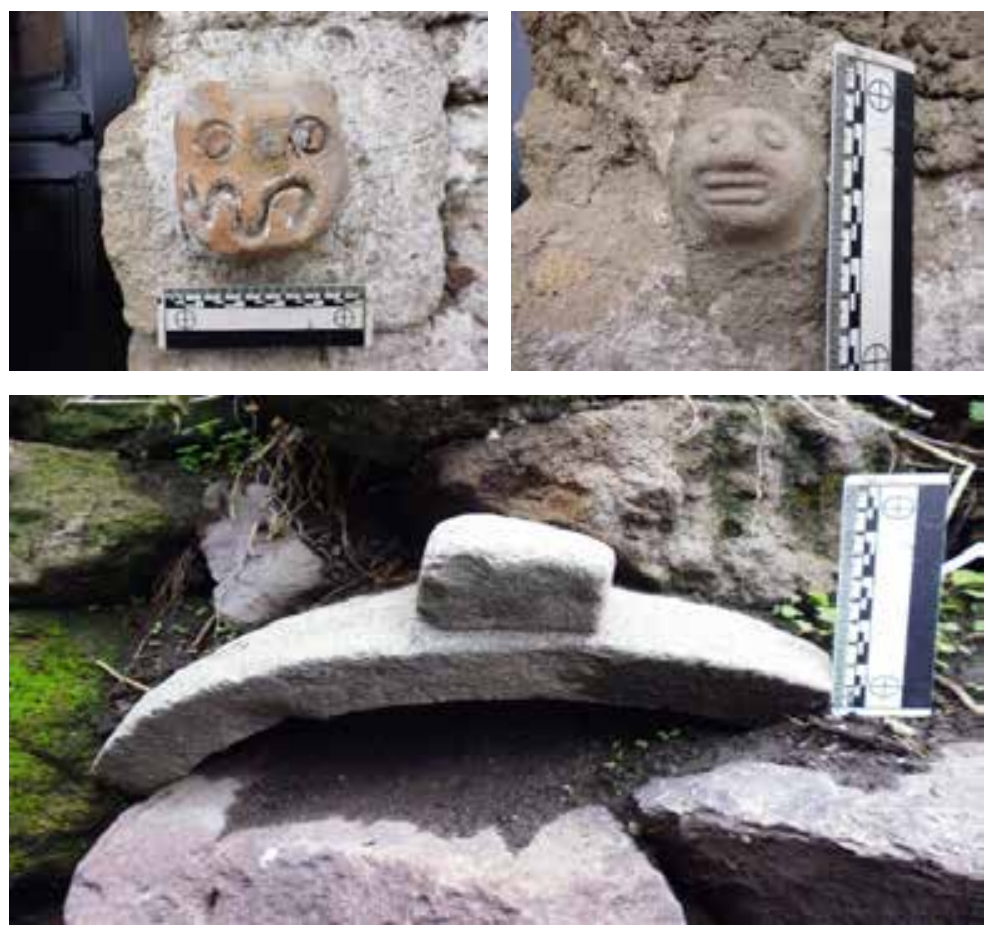

Figuras 27, 28 y 29: Vista de materiales observados en los alrededores del sitio Jollqemarca.

\section{SEPRISPAMPA}

Se localiza al lado oeste del anexo de Calquimarca, se encuentra ubicada en una ladera muy próxima a la carretera a Conococha, en las coordenadas UTM: 18L 0243811E, 8875577N, a una altitud de 3617 msnm. Políticamente se ubica en los territorios del anexo de Calquimarca, distrito de Cajacay, provincia de Bolognesi, Región Ancash. El acceso es mediante camino que se dirige desde el poblado de Calquimarca hacia el oeste por 5 minutos de caminata, próximo a viviendas contemporáneas.

Está conformado por un abrigo rocoso, pinturas rupestres y terrazas. Se trata de un abrigo rocoso con una orientación de este a oeste, cuyas medidas son 6 metros de largo, 2 metros de altura y una profundidad de 2.50 metros. En la parte plana de la roca se aprecia pintura en color rojo ocre, que corresponde a dos zorros en posición detenido y en posición de perfil mirando fijamente al lado derecho del abrigo rocoso, con las orejas levantadas y con la cola enroscada. Al lado izquierdo se encuentran motivos geométricos, se trata de dos soles irradiados de color rojo, alterada en tiempos contemporáneos con tiza de color blanco, Así mismo, se encuentran motivos amorfos dispersos a manera de manchas, motivos no identificados por estar alterados por el medio ambiente. Al lado norte del interior del abrigo (parte izquierda) y adosado a la pared, presenta una capa de arcilla y sobre ella presenta pinturas rojas dispersas.

Terrazas: Se tratan de construcciones con una orientación de sur a norte y una longitud que varía, desde 20 hasta 150 metros de largo (la más grande). La técnica constructiva es el pircado con argamasa, de una sola hilada, con piedras grandes en la parte baja del muro y piedras medianas en la parte 
superior. Las terrazas están constituidas por muros de contención de variable altitud, que alcanza hasta 1.80 metros y las piedras utilizadas son de tipo basalto de formas irregulares, obtenidos de canteras del mismo lugar.

El sitio corresponde al Intermedio Tardío. La cueva y abrigos rocosos presentan una alteración por parte de animales como vacunos y ovinos, que han dejado abundante estiércol.

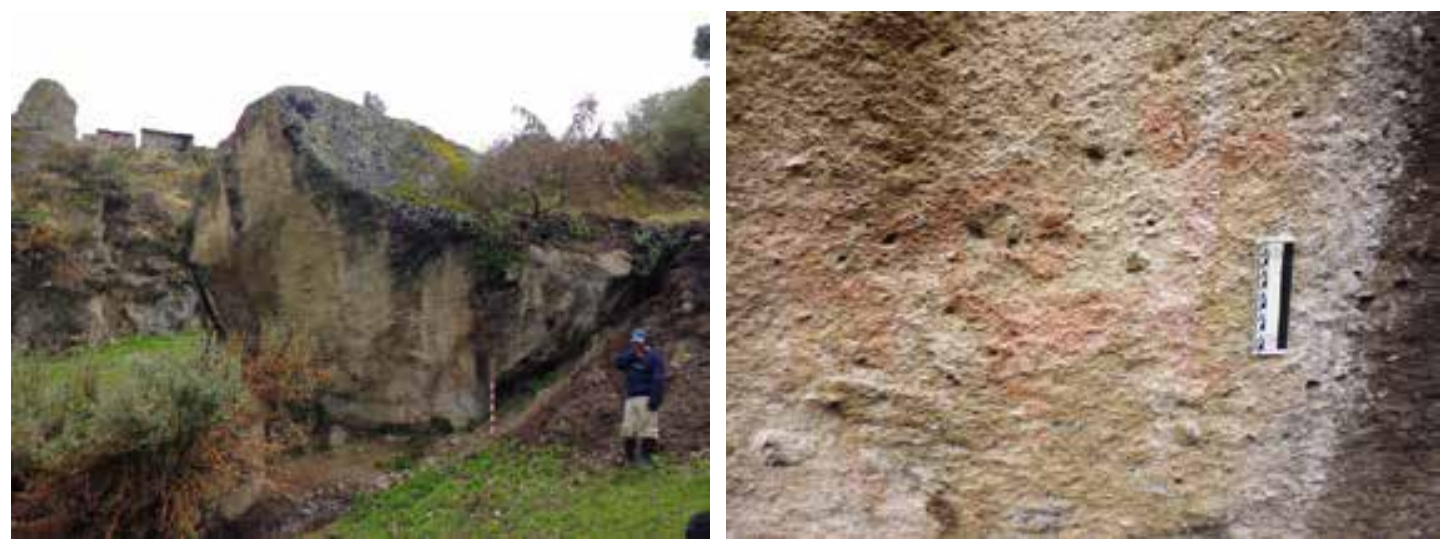

Figura 30: izquierda: Vista panorámica del abrigo rocoso y pintura rupestre del Sitio de Seprispampa. Figura 31: Derecha: Vista de detalle de pintura rupestre de motivo zoomorfo Sitio de Seprispampa.
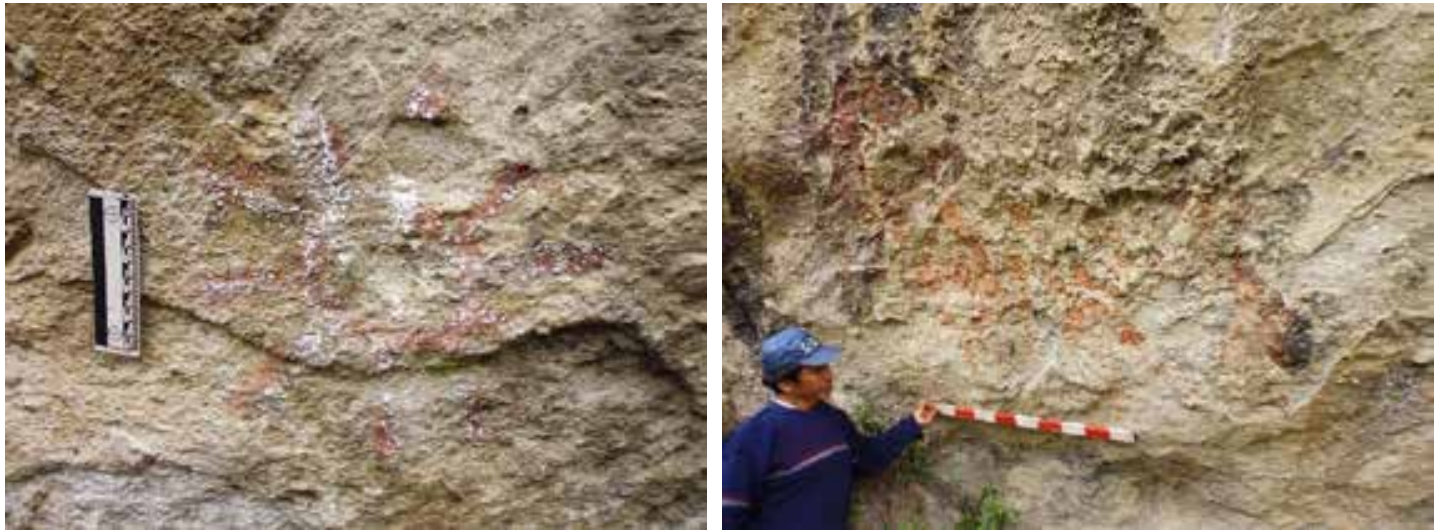

Figuras 32 y 33: Vista de dos pinturas rupestres.

\section{JACRAN}

El sitio se ubica en un peñón limitando entre Guambo (provincia de Recuay) y el caserío Callquimarca (Bolognesi), al noreste del caserío de Santa Rosa en las coordenadas de UTM: 18L 0243436E, $8875545 \mathrm{~N}$, a una altitud de 3492 m.s.n.m. Políticamente se encuentra en la jurisdicción del poblado actual del caserío de Callquimarca, Distrito de Cajacay, provincia de Bolognesi, región Ancash. El acceso es mediante un camino por medio de las chacras de cultivo que se dirige desde el actual poblado de Callquimarca con dirección al oeste, pasando por el sitio arqueológico de Seprispampa, hasta llegar al sitio. 
Conformado por un peñón en la cual se encuentra un abrigo rocoso con pinturas rupestres, en la parte alta del farallón. Las pinturas de color rojo se presentan a manera de manchas dispersas. Se encuentra en regular estado de conservación, la pintura está sufriendo alteración ambiental ya que se encuentra expuesta al aire libre.

\section{Dos Ventanas}

El sitio se ubica en un farallón cerca a la cima del Cerro Dos Ventanas, al lado sur del caserío de Ámbar, en las coordenadas UTM: 18L 0240319E, 8876907N, a una altitud de 3317 m.s.n.m. Políticamente se encuentra en la jurisdicción del poblado actual de Ámbar, Distrito de Cajacay, provincia de Bolognesi, región Ancash. El acceso es mediante un camino que asciende una ladera que se dirige desde el poblado de Ámbar con dirección al sur hasta llegar al sitio.

Se trata de dos abrigos rocosos que se encuentran en la parte media del farallón, orientado de oeste a este, con 10 metros de largo por 1.36 metros de profundidad y una altura de 1.80 metros. En el interior se encuentra una pequeña estructura rectangular tipo chullpa, con compartimientos y técnica constructiva de mampostería simple con mortero de barro. Tiene 1.20 metros de largo, con muros de $0.60 \mathrm{~m}$ de ancho y una altura conservada hacia el interior de 1 metro. La estructura presenta al interior piedras caídas del muro y material óseo humano como: costillas, fémur, cráneos y distintas partes desarticuladas dispersas. Así mismo, en la pared del abrigo presenta manchas de hollín, se hallaron artefactos y soguillas trenzadas de material vegetal.

La segunda estructura funeraria se encuentra en un abrigo rocoso, en un lugar inaccesible, ya que está en la parte media del farallón y en el interior presenta una estructura funeraria de planta rectangular, construida a base de piedras canteadas con mortero de barro y en la parte superior presenta pinturas rupestres de color rojo a manera de manchas rojas dispersas en toda la dimensión de la estructura.

Asociado a las estructuras funerarias (lado norte) se encuentran terrazas discontinuas, con una orientación de sur a norte y una longitud que varía, desde 10 hasta 15 metros la más grande. La técnica constructiva es el pircado de una sola hilada con piedras grandes en la parte baja del muro y las piedras medianas en la parte superior. Las terrazas están constituidos por muros de contención de variable altitud que alcanza hasta 1.80 metros y las piedras utilizadas son de tipo basalto de formas irregulares

Según el tipo de material recuperado se asocia a Intermedio Tardío, aunque no se puede descartar ocupaciones más tempranas. 


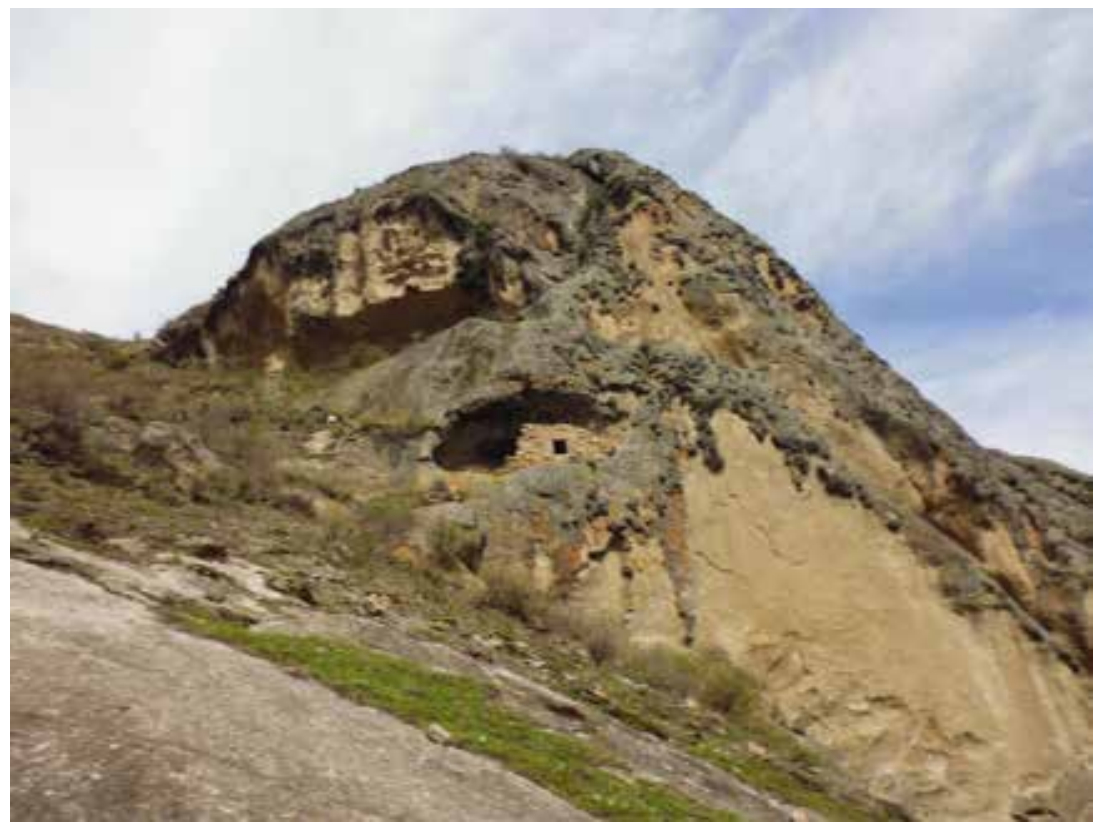

Figura 34: Vista Panorámica del Sitio Dos ventanas, se aprecia el abrigo rocoso con la estructura funeraria.

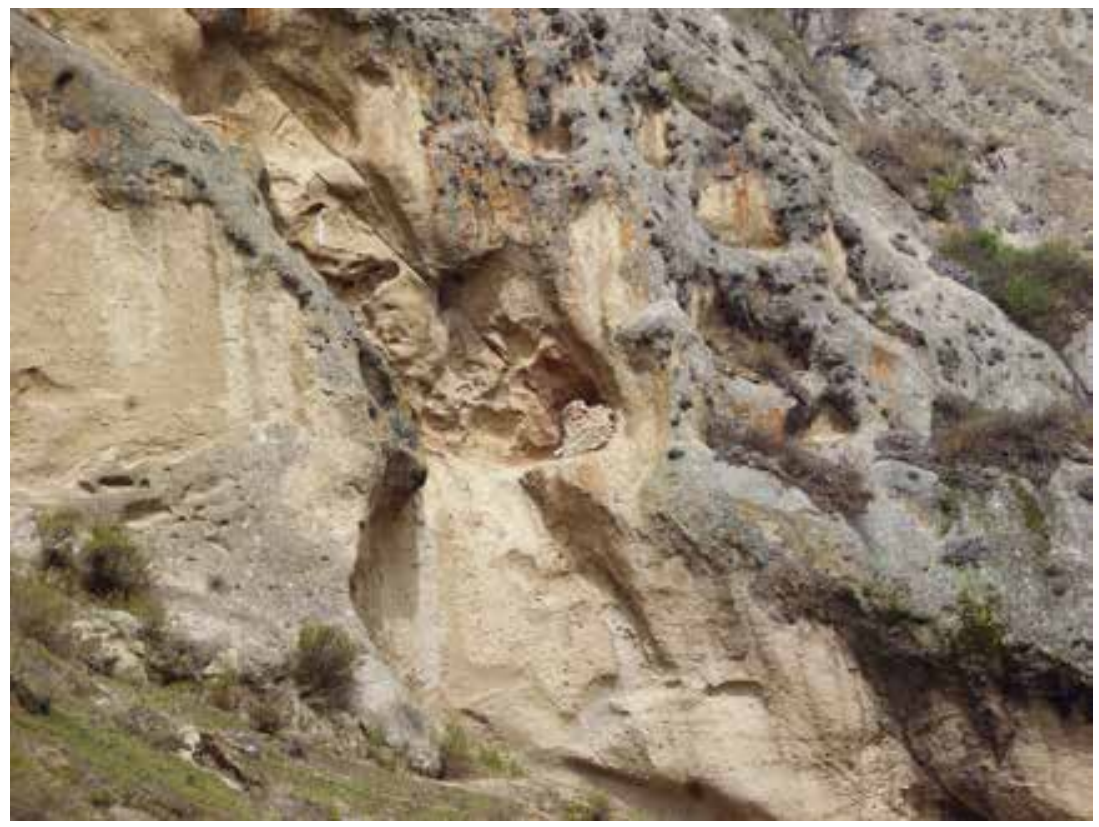

Figura 35: Vista de detalle del sitio Dos Ventanas, se aprecia el abrigo rocoso con la estructura funeraria con evidencia de pictografía roja, a maneras de manchas. 


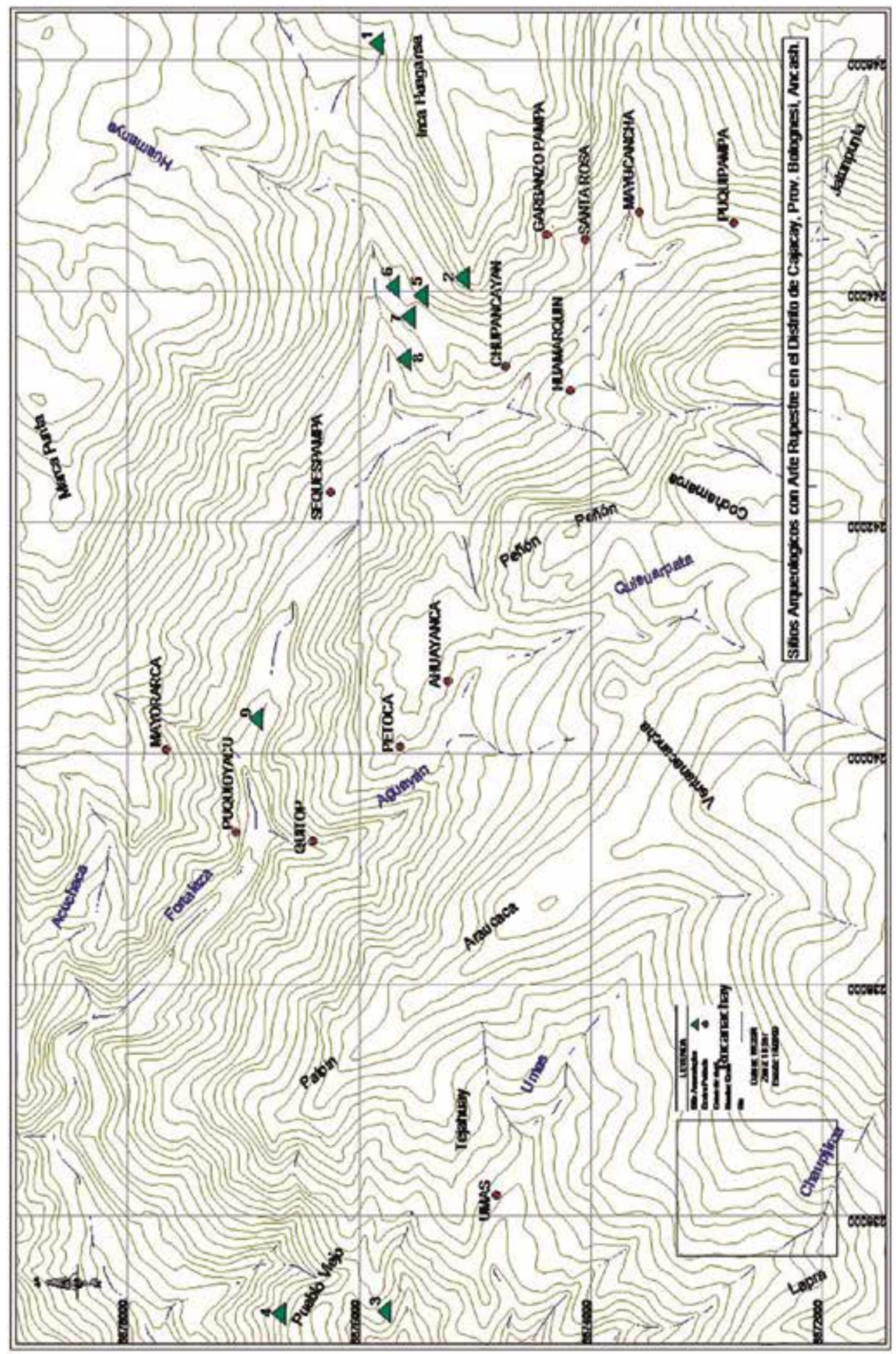

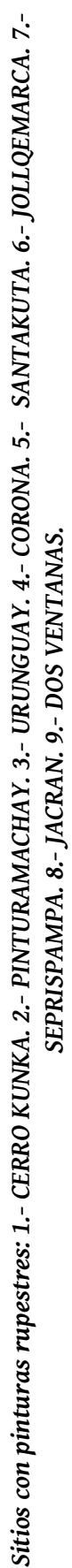




\section{INTERPRETACiones Culturales}

Son muy escasas las investigaciones sociales desarrolladas en el distrito de Cajacay, en la cuenca alta del río Fortaleza y en la provincia de Bolognesi.

En primer lugar, cabe señalar los valiosos aportes del Dr. Román Robles Mendoza, sobre las características sociales de las comunidades campesinas de las provincias de Bolognesi y Ocros como: Raquia, Marca, Huayapampa, Yamor, Cajacay, Chilcas, Acas, entre muchas otras (Robles; 2007, 2009); así como de sus manifestaciones culturales (Robles; 2000, 2005, 2015).

De igual manera son importantes las investigaciones del Dr. Filomeno Zubieta Núñez (2003a, 2003b, 2008), quien durante los últimos 20 años ha venido realizando investigaciones socioculturales sobre las diversas comunidades de la provincia de Bolognesi, en especial en el distrito de Chiquián y la Comunidad Campesina de Cuspón, registrando sus tradiciones, festividades, religiosidad, proceso histórico, gastronomía, mitos, leyendas, etc.

Con respecto a las investigaciones arqueológicas realizadas en la zona, salvo los trabajos de Pieter van Dalen $(2007 ; 2013)$ en los sitios de Palpín en Cajacay y San Ignacio en Yamor, no existen mayores investigaciones en nuestra área de estudio. Por otra parte, cabe señalar, las limitadas investigaciones de Arturo Ruiz Estrada en el distrito de Chiquián (Ruiz; 2003a, 2003b, 2008, 2009), los cuales tienden a la generalidad y vaguedad de información.

Se conoce que, en la Colonia, Cajacay y sus alrededores fueron el escenario de feroces campañas de extirpación de idolatrías que conllevaron a destruir numerosos centros ceremoniales (Duviols; 1986, Huertas; 1981, Pereyra; 1989, Sánchez; 1991).

Es importante señalar también, el trabajo de investigación desarrollado por los arqueólogos Sheyla Melgar y Ernesto Lázaro (2007) en la localidad de San pedro de Copa, donde identifican el patrón de asentamiento para el Intermedio Tardío a partir del registro de 10 sitios arqueológicos, entre sitios ceremoniales, tumbas aisladas, sitios de habitación y sitios funerarios.

De igual manera el 2012 se realizó una prospección arqueológica en los distritos de Ocros, Acas y Chilcas de la provincia de Ocros, registrando más de 40 sitios arqueológicos y definiendo sus características (van Dalen, Bravo, Castillo, Alfaro y Marcelo; 2014).

Es importante mencionar el trabajo de Benjamín Nieto (1991) en el cual reporta las festividades tradicionales desarrolladas en el distrito de Ocros, así como el trabajo de Manuel Nieves (2015) sobre las tradiciones orales del distrito de Canis, al igual que los estudios de Mario Reyes (2002) sobre el distrito de Chiquián.

Con respecto a pinturas rupestres en los alrededores de Cajacay, se ha realizado investigaciones en los alrededores de Raquia y Yamor, identificando numerosos sitios con pinturas rupestres (van Dalen, Obregón y Allende; 2015). Existen en las partes medias y altas de la cuenca alta del río Fortaleza, numerosos sitios con pinturas rupestres o quillcas. Se encuentran ubicados sobre las paredes verticales de afloramientos rocosos o al interior de abrigos. Se trata de una larga tradición de quillcas desarrollada desde el periodo Intermedio temprano, elaborada sobre rocas con alto contenido de hierro, lo que les da una coloración rosácea o rojiza a las paredes rocosas, sobre las cuales se han elaborado los motivos antropomorfos, zoomorfos, geométricos, círculos, círculos con punto concéntrico y estilizados en colores blanco y rojo. Algunas quillcas están elaboradas en técnica de negativo. En asociación directa a estas quillcas siempre encontramos estructuras funerarias tipo chullpas. Las quillcas se pueden encontrar a diferentes altitudes con respecto a la superficie del suelo. La mayoría de quillcas, 
por hallarse en exposición directa al medioambiente, se encuentran en proceso de destrucción, pues en muchos casos se está perdiendo el color de los motivos.

\section{Conclusiones}

Se ha presentado las características de nueve sitios arqueológicos con pinturas rupestres o quillcas, ubicados en los alrededores del pueblo de Cajacay, en la cuenca alta del río Fortaleza. Muchos de estos sitios presentan las pinturas asociadas a estructuras funerarias tipo chullpas. Entre las representaciones que se observan, tenemos motivos antropomorfos, con personajes con o sin tocados sobre la cabeza y en posición parada o en movimiento; representaciones zoomorfas, entre los que destacan figuras de zorros y aves; representaciones geométricas y de soles.

\section{Bibliografía}

DUVIOLS, Pierre

1986 Cultura andina y represión. Procesos y visitas de idolatrías y hechicerías en Cajatambo, siglo XVII. Centro de Estudios Rurales Andinos Bartolomé de las Casas. Cusco, 570 pp.

\section{HUERTAS VALLEJOS, Lorenzo}

1981 La religión en una sociedad rural andina, Siglo XVII. Universidad Nacional San Cristóbal de Huamanga. Ayacucho, $158 \mathrm{pp}$.

MELGAR TORRES, Sheyla y LÁZARO TORRES, Ernesto

2007 “El periodo Intermedio Tardío en San Pedro de Copa: una aproximación al patrón de asentamiento". Kullpi. Investigaciones culturales en la provincia de Huaral y el Norte Chico. Huaral, pp. 243-268.

NIETO ROSALES, Benjamín

1991 Ocros, tierra del encanto. Historia y esperanza de un pueblo. Lima, 175 pp.

NIEVES FABIÁN, Manuel

2015 Narrativa oral de la zona sur de la provincia de Bolognesi. En el cincuentenario de la creación política del distrito de Canis 29 de enero de 1965 - 2015. Edición Wamanwaka. Huánuco, 110 pp.

ONERN

1972 Inventario, evaluación y uso racional de los recursos naturales de la Costa: Valle Fortaleza - Paramonga. Oficina Nacional de Evaluación de Recursos Naturales (ONERN) II Tomos. Lima.

PEREYRA PLASCENCIA, Hugo

1989 “Chiquián y la Región de Lampas entre los siglos XVI y XVII: una hipótesis sobre el origen de las campañas de extirpación de idolatrías en el Arzobispado". Boletín del Instituto Riva Agüero, № 16. Pontífice Universidad Católica del Perú. Lima, pp. 21 - 54.

REYES BARBA, Mario

2002 Chiquián. La incontrastable villa. Compendio histórico de un pueblo en transformación. Lima, 149 pp. 
ROBLES MENDOZA, Román

1996 Chiquián: Tradición y modernidad. Facultad de Ciencias Sociales, Universidad Nacional Mayor de San Marcos. Lima, 83 pp.

2000 La banda de músicos: las bellas artes musicales en el sur de Ancash. Instituto de Investigaciones Sociales, Facultad de Ciencias Sociales, Universidad Nacional Mayor de San Marcos. Lima, $362 \mathrm{pp}$.

2005 “Las iglesias andinas: huellas de la cristianización y religiosidad popular". Revista de Antropología. Cuarta época. Año III, № 3. Universidad Nacional Mayor de San Marcos. Lima, pp. $103-162$.

2007 "El mensaje de los mitos: héroes fundadores y origen de los alimentos en la memoria de los pueblos andinos”. Revista de Antropología. Cuarta época, año V, № 5. Universidad Nacional Mayor de San Marcos. Lima, pp. 91 - 132.

2009 "Las comunidades campesinas en el proceso de desarrollo de los pueblos". Kullpi. Investigaciones culturales en la provincia de Huaral y el Norte Chico. Año 4, № 4. Pieter van Dalen, editor. Huaral, pp. 113 - 126.

2010 “Danzas andinas: simbología e identidad cultural”. Folclore. Arte, cultura y sociedad, Revista del Centro Universitario de Folclore. Universidad Nacional Mayor de San Marcos. Lima, pp. 59-98.

2015 "Representaciones de la memoria en los eventos festivos andinos". Investigaciones Sociales. Instituto de Investigaciones Sociales, Facultad de Ciencias Sociales, Universidad Nacional Mayor de San Marcos. Lima, pp. 11-30.

RUIZ ESTRADA, Arturo

2003a “El poblamiento prehispánico de Cuspón”. Cuspón. Comunidad e Identidad. Filomeno Zubieta, Editor. Ed. Imagen. Huacho, pp. 67-86.

2003b “Antiguas ocupaciones humanas en Cuspón: provincia de Bolognesi”. Arqueología de la sierra de Ancash. Propuestas y perspectivas. Bebel Ibarra, editor. Lima, pp. 405-416.

2008 “Patrimonio arqueológico de Chiquián”. Chiquián. Arqueología, Identidad y Turismo. Ed. Imagen. Huacho, pp. 9-50.

2009 “Capillapunta: un asentamiento prehispánico en Chiquián”. Kullpi. Investigaciones culturales en la provincia de Huaral y el norte chico. $\mathrm{N}^{\circ} 4$. Lima, pp. 209-218.

SÁNCHEZ, Ana

1991 Amancebados, hechiceros y rebeldes (Chancay, siglo XVII). Centro de Estudios Rurales Andinos Bartolomé de las Casas. Cusco, 208 pp.

VAN DALEN LUNA, Pieter

2004 "Los valles de Chancay y Huaura dentro del Tahuantinsuyo". Boletín de Patronato de Defensa del Patrimonio Cultural en los valles de Huaura y Ambar, № 16. Huacho, 8 pp.

2007 "Palpin: un asentamiento con arquitectura funeraria en el alto Fortaleza, Cajacay, Ancash". Tukuy Rikuq, N² 4. Lima, pp. 51-57. 
2008 Los ecosistemas arqueológicos en la cuenca baja del río Chancay - Huaral: su importancia para el desarrollo de las formaciones sociales prehispánicas. Ed. Gutemberg. Lima, 192 pp.

2011 “El Tawantinsuyu en la costa norcentral peruana: valles de Chancay y Huaura". Investigaciones Sociales $\mathrm{N}^{\circ}$ 27. Instituto de Investigaciones Sociales, Facultad de Ciencias Sociales. Universidad Nacional Mayor de San Marcos. Lima, pp. 77-103.

2012 “Arqueología tardía del valle Chancay-Huaral: identificando la nación Chancay". Investigaciones Sociales $\mathrm{N}^{\circ}$ 28. Instituto de Investigaciones Sociales, Facultad de Ciencias Sociales. Universidad Nacional Mayor de San Marcos. Lima, pp. 271-283.

2013 "San Ignacio, un sitio arqueológico tardío en Yamor, distrito de Antonio Raymondi, provincia de Bolognesi, Ancash”. Tiempos, revista de historia y cultura $\mathrm{N}^{\circ}$ 8. Lima, pp. 107-122.

2016 “Contextos funerarios atavillos en Purunmarca, Vichaycocha - Huaral”. Arqueología y Sociedad, № 30. Museo de Arqueología y Antropología, Universidad Nacional Mayor de San Marcos. Lima, pp. 39-100.

VAN DALEN LUNA, Pieter; BRAVO MEZA, Bradymir; CASTILLO VALLE, Rosario; ALFARO SILVA, Diana; MARCELO GONZÁLES, Yerovi.

2014 "Introducción al estudio arqueológico de la provincia de Ocros, Ancash. Distritos de Ocros, Santiago de Chilcas y Acas". Investigaciones Sociales $N^{\circ}$ 32. Instituto de Investigaciones Sociales, Facultad de Ciencias Sociales. Universidad Nacional Mayor de San Marcos. 2014. Lima, pp. 89-102.

VAN DALEN LUNA, Pieter y OBREGÓN PILLACA, Hamilton

2016 "La fiesta de San Bernardo de Yamor y la participación del Inca con las Pallas, Bolognesi - Ancash”. Actas del XIX Congreso Nacional de Folclore. Centro universitario de Folclore, Universidad Nacional Mayor de San Marcos, Lima. En prensa.

VAN DALEN LUNA, Pieter; OBREGÓN PILLACA, Hamilton; ALLENDE JOAQUÍN, Daniel

2015 “El arte rupestre de Yamor, cuenca alta del río Fortaleza, Bolognesi - Ancash". Arqueología y Sociedad № 29. Museo de Arqueología y Antropología, Universidad Nacional Mayor de San Marcos. Lima, pp. 407-461.

ZUBIETA NUÑEZ, Filomeno

2003a Por la ruta del Huayhuash. Los recursos Turísticos de la provincia de Bolognesi. Huacho, 150 pp.

2003 b Cuspón. Comunidad e identidad. Huacho, 87 pp.

2008 “Chiquián: cultura e identidad”. Chiquián. Arqueología, identidad y turismo. Arturo Ruiz, Filomeno Zubieta y Roberto Aldave, editores. Lima, pp. 50-106. 
